\title{
OOPS! THE CRITICAL ROLE OF RISK-TAKING AND FAILURE IN EDUCATIONAL CHANGE AND TEACHER EDUCATION
}

\author{
Maya Wizel \\ Middlebury College (USA) \\ Hacking Education (Israel)
}

\begin{abstract}
Traditional educational systems need to change. They need to be more innovative. However, innovation carries a risk - it sometimes fails. Qualitative research conducted with teachers who changed and implemented their pedagogy in innovative ways ("hacks") in their classroom formed the foundation of a new framework to meet this need-teachers as "hackers." These teachers' characteristic habits and behaviors contribute to their success in creating islands of change in public schools. The participants volunteered their stories of pedagogical failures - class plans that flopped, technological tools that fizzled, and projects that fell short of their learning goals. They not only shared their cases, but also approached those failures as a natural and inherent part of becoming adaptive educators. This paper explores the role of failure and risk-taking in educational settings with the aim to encourage rethinking and opening our practices to development by making mistakes. As one participant described innovative pedagogy, "You have to be willing to fail in public."
\end{abstract}

Keywords: Risk-taking, change, failure, innovation, education.

\section{Introduction}

In lectures, conferences, and educators' professional development sessions where current research regarding teachers who hack their pedagogy is discussed, the issue of risk-taking and failure is often the most controversial. It raises questions and evokes emotional discussion. Attendees verbalize, for example, "We do not have a culture of risk-taking in schools" and "How can we discuss failure when we discuss education? We're talking about kids' lives." The goal of this paper is to shed some light on that intersection of innovation, risk-taking, failure, and learning in public education settings.

\subsection{Innovation, risk-taking, and failure}

Failure is a complex phenomenon (Edwards \& Ashkenazy, 2018). It used to be described as the end of things; now, it is part of the way forward (Loscalzo, 2014). In our constantly changing world, we are slowly shifting from talking about successes toward discussing failures (Loscalzo, 2014; Wang et al., 2018) and the often-opposing relationship between error and innovation (Bauer \& Harteis, 2012). For instance, in the entrepreneurship field, most innovation studies are still based on success stories despite indications that "the experience of failure may be a substantial source for the improvement of entrepreneurship knowledge and skills after a failure" (Atsan, 2016). Clearly, as Loscalzo (2014) explained, "Failure has at least as important a role in our experience, education, and professional development as success - if we would only learn from it."

A discussion of failure is also about learning, developing, and improving future outcomes (Atsan, 2016; Edwards \& Ashkanazy, 2018; van Woerkom, 2012). "Errors can be seen as a natural by-product of active learning: As learners actively explore the environment, errors will inevitably occur. Conversely, the dogma of zero-error tolerance that exists in many organizations may unintentionally promote risk avoidance" (van Woerkom, 2012, p. 130).

In 2012, an organization in Mexico founded "Fuckup Nights," events that have since spread internationally (Birrane, 2017). During these activities, individuals from diverse backgrounds share their stories of professional failure. These tales both inspire the audience and support the idea that any change or innovative action - as in any action in an age of uncertainty_risks failure. Such events, as well as other means that emphasize learning from failure, transform failure from something hidden and shame-ridden to a legitimate outcome. Once failure is legitimatized, it is possible to learn from and improve upon it. 


\subsection{Risk-taking and failure in non-educational fields}

In the high-tech industry, risk-taking often permeates the cultural organization and is built into job descriptions (Edmondson, 2011; Grossmann, 2014). Demonstrating the growing interest in learning better from failures, teams from over 50 technology-industry firms recently participated in Wang et al.'s (2018) study in Beijing, China to explore learning from failure, as well as issues of shame related to failing. Wang et al. measured learning from failure as well as professional commitment and shame. They recommended that support, enhanced sense of belonging, and as guidance regarding how to deal with shame and negative feelings after failure can create an organizational culture of learning and development.

Studies in the medical field found organizational and personal factors related to learning from failures. For example, Edmondson (2004) reported, "Interpersonal climate often inhibits speaking up with questions, concerns, and challenges" (p. ii5) and that the professional culture tends to have quick fixes to problems instead of supporting root cause analysis and systematic learning from mistakes. Edmondson also demonstrate how consistent work to create a blame-free work environment and teams that learn and develop from mistakes improve healthcare and save lives. Taking this concept a step further, Loscalzo (2014) wrote about the education process for medical students and claimed that we should not ignore failure, but celebrate it. Even if celebrating failure sounds like a big step to some of us, we can all understand that it carries opportunities to learn, develop, and promote change in complex systems.

\subsection{Risk-taking and failure in education}

An Organisation for Economic Co-operation and Development report, which focused on driving innovative and equitable change in complex education systems, devoted a full chapter to failure, entitled, "Learning to Fail, Not Failing to Learn" (Burns \& Köster, 2016). It emphasizes the dichotomous relationship between innovation and error-some policies pressure the education system to change and innovative, while other regulatory forces pressure them to reduce failure. Indeed, exploring innovation and change in education systems reveals a conundrum: On one hand, leadership and policymakers encourage innovation in their education systems. On the other hand, these same administrators seek to maintain the status quo and avoid errors (Brown \& Osborne, 2013; Burns \& Köster, 2016). The message seems to be, "Innovation is fine, but only if it succeeds."

Stakeholders in the education arena (policy makers, teachers, researchers, parents, and, of course, students) face a range of risks with a variety of approaches (Blanchenay \& Burns, 2016). Brown and Osborne (2013) described - and then criticized - the common approaches to this junction of innovation, education systems, and risk-taking. The first approach is risk minimalization, meaning avoiding risk and thus its connection to innovative processes. The second is risk analysis. They claimed that this approach's aim of minimizing risk consequences does not fit complex systems such as education (Blanchenay \& Burns, 2016).

Instead, Brown and Osborne (2013) introduced two approaches to risk-taking and failure that offer a system of managing the risk of new actions, as well as highlighting the risk of inaction. They offered to develop a governance system to learn from failures as well as from successes. In what they termed transparent risk governance, "risks are openly acknowledged to all relevant stakeholders" (Blanchenay \& Burns, 2016, p. 208). However, imagining such an approach in a school setting seems almost impossible-imagine parents' reactions when you tell them, "We will try to teach algebra in a flipped classroom model, but it might not work."

Similarly, Blanchenay and Burns (2016) emphasized two optional actions: "Through experimentation, i.e. the testing of innovative programmes in a limited magnitude and scope; as well as by developing a governance system that can learn from failures as well as successes" (p. 207). Their study inquired into pedagogical risks within a classroom but also provided insight into associated risk approaches, attitudes, and behaviors at broader segments, such as the school, district, or countries level.

\section{Research design and general results}

The participants of the current "Teachers as Hackers" study were eight public school teachers from Massachusetts who had more than 1 year experience in the profession, worked in the classroom, and demonstrated pedagogic innovation. The participating teachers came from a variety of school environments, subjects, professional backgrounds, and years of experience. Each had explored new ways to teach or incorporate nontraditional methods - such as innovative class design, project-based learning, new assessment tools, interdisciplinary perspective, or technology integration-into their teaching. These innovative actions and pedagogical explorations were individual efforts and not part of a broader reform. The data were collected using qualitative methods, primarily interviews. 
The study results indicated a general profile of teachers as hackers - that is, teachers implementing their pedagogy in innovative ways. In general, teachers who hack are ideological and passionate about education; teaching is not only their passion but also part of "who they are.". They are highly motivated to improve their teaching processes and use their diverse backgrounds to influence their practice. They are self-reflective, constantly exploring ways to improve their pedagogy. In addition, they appreciate learning in communities of practice and try to be part of a physical or virtual professional learning community. Teachers who hack do not necessarily have more resources (e.g., time, space, or technology); instead, they utilize their limited but available resources wisely and effectively. The two most surprising themes that emerged from the qualitative analysis were their propensity for risk-taking and overcoming fear of failure. Simply stated, teachers who act as hackers follow a need or a problem, use creativity and playfulness, and take risks doing something they had never before tried in the classroom.

\section{Results: risk-taking and failure}

Teachers who hack are driven to explore new ways of practice. In this process of exploration and improvement, they take risks and wisely use the resources around them to reach their goals. For example, one participant talked about other teachers and the risk of not being able to adopt technology: "They get worried, 'What if I do something wrong?' I just don't think about it in that way." Indeed, teachers who hack are willing to act in the face of uncertainty and to let go of the need to know everything. One recalled, "When I launched into it . . . I didn't know what I was doing." Another participant reflected about the broader challenges of taking risks: "Almost everyone talks about fixing middle school, almost no one wants to do it with their own child. It is a big risk, especially if you are in a relatively successful affluent community. [Parents feel] the status quo worked well enough for [them] and so it is very scary to go away from that."

These teachers understand that there are many possible answers to the question of how we should conduct education in the 21 st century. As one stated, "A lot of people I have interacted with feel worried where[as] I definitely grew up thinking, "You just try it and if it doesn't work, you try something else."” Teachers who hack accept failure as part of the improvement process and acknowledge that technology offers endless possibilities to change their pedagogy. They are unashamed to share their failures. As one described, "I've made far more mistakes in the process than I have right decisions, and being open and honest in learning about that was probably the best." Nevertheless, they reflect constantly: "It's by no means as successful as I wish it was." Finally, these teachers also see the educational benefits of making mistakes. "It's good for students to see adults grappling with problems like that... I can remember as a kid, I thought teachers just knew everything-you grow up and you know it all."

One teacher's statement about his own attitude change summarizes the study participants' openness about how natural it is to fail when aiming to change and innovate in education and their willingness to embrace uncertainty: "I'm embracing that myself. Getting over the idea that it's going to be perfect or all done at once. It's a multi-year project and I have to accept that."

\section{Discussion and recommendations}

Risk-taking behavior connects well with pedagogy, innovation, and failure. In addition to a personal inclination toward taking risks, risk-taking by teachers who hack seems to increase with their experience and professional confidence. Although traditionally not considered a quality of good teachers, risk-taking dominates change theory (e.g., Heifez, Linsky \& Grashow, 2009).

Robinson (2009) showed that fear can prevent people from entering a situation in which they feel threatened; thus, they lose a possible learning experience (Jarvis, 2012). Mezirow (1994) referred to similar emotions and claimed the first phase of a learning process is a disorienting dilemma. However, the tendency to be ashamed and to avoid or hide failure is natural.

Human beings are also inherently reluctant to acknowledge their failures, disappointments, and misadventures-largely because of the fear of shame and embarrassment among important others. The desire to be seen as capable and competent is especially important in the workplace, where successes are typically rewarded and

failures punished. (Edwards \& Ashkenazy, 2018, p. 169)

This natural inclination makes the fact that all study participants shared their failures without being asked even more impressive.

Van Woerkom (2012) found team members more likely to suggest new ideas in an environment that has a healthy approach to problem-solving mistakes than in an atmosphere of blame. However, in practice, discussion of the risks of inaction is almost nonexistent. In an era of uncertainty, the status quo is often perceived as "good enough," but the reality is more complex. If we want our schools to change, we 
need to let risk-taking and failure enter the gate. We need to acknowledge - if not celebrate-failure as much as we celebrate success. Embracing failure is a key factor to transforming education. We can experiment at the individual, as well as the policy, level (Blanchenay \& Burns, 2016). "Policy experimentation aims to improve the system by explicitly testing new policy options and assessing which could be successfully generalized" (p. 168). Other complex public sectors, such as health care and economics, have already implemented such policy options.

A related issue is the level of autonomy that individuals and teams have - an autonomy that can encourage them to deal with failure and learn from it appropriately.

It is crucial for education systems to anticipate those risks, both in terms of establishing

a process for governing risk and developing a transparent and reactive way to make decisions about the kinds of risks that are acceptable in any given situation. But there is another element of the process that is equally important: education systems must accept that taking risks (in experimentation and indeed in any kind of innovation) means that there is a possibility of failure. (van Woerkom, 2012, p. 213)

The cases described in this "teachers who hack" study are local, and the participants who implemented the innovations claimed they had not been able to scale them up to an entire school or even a department. Blanchenay and Burns (2016) explained this phenomenon, claiming that "in a complex system, bottom-up initiatives cannot be scaled up to the broader system without at least some level of centralized discussion" (p. 173).

Despite the shift from talking about successes toward discussing failures (Loscalzo, 2014; Wang et al., 2018), much work is still needed to create a culture of constructive learning from mistakes (van Woerkom, 2012). Thus, my paradoxical recommendation is to devote more research to the somewhat neglected area of innovation risk management in the public sector - a recommendation with inherent risks. "At the micro-level, formative work is required to explore the processes through which individual users, citizens, politicians, service professionals, and other stakeholders will engage in risk governance for innovations in public services" (Brown \& Osborne, 2013, p. 204).

\section{Summary}

Who wants to talk about failure? It may be nicer to cut ribbons and celebrate success - but there can be no ribbons if we do not manage risk and transform it with more transparency. Risk-taking is becoming a core skill (Rolfe, 2010). When discussing risk-taking, we must bear in mind the underlying risk that exists every day in schools - the risk of inaction, of not changing, of keeping the status quo and failing daily without acknowledging the failures (Blanchenay \& Burns, 2016).

We should promote an organizational culture that breaks the connection between failure and negativity (Wang et al., 2018). If we want innovative education, we need to be open for possible innovation failures (Wizel,2018).

Although this paper may seem devoted to failure, it embraces that risk-taking also offers the satisfaction of success. As one participant shared, "I have to tell you that this one, from the first run, it just exploded and everything was far beyond my imagination how well it went."

\section{References}

Atsan, N. (2016). Failure experiences of entrepreneurs: Causes and learning outcomes. Procedia: Social and Behavioral Science, 235, 435-442. doi:10.1016/j.sbspro.2016.11.054

Bauer, J., \& Harteis, C. (Eds.). (2012). Human fallibility: The ambiguity of errors for work and learning. Dordrecht, Netherlands: Springer.

Birrane, A. (2017, March 13). Yes, you should tell everyone about your failures. BBC. Retrieved from https://fuckupnights.com/

Blanchenay, P., \& Burns, T. (2016). Policy experimentation in complex education systems. In T. Burns \& F. Köster, Governing education in a complex world (pp. 161-186). Paris, France: OECD.

Brown, L., \& Osborne, S. P. (2013). Risk and innovation. Public Management Review, 15, 186-208. doi:10.1080/14719037.2012.707681

Burns, T., \& Köster, F. (2016). Governing education in a complex world. Paris, France: OECD Publishing.

Edmondson, A. C. (2011, April). Strategies for learning from failure. Harvard Business Review. Retrieved from https://hbr.org/2011/04/strategies-for-learning-from-failure

Edmondson, A. C. (2004). Learning from failure in health care: Frequent opportunities, pervasive barriers. BMJ Quality \& Safety, 13(Suppl 2), ii3-ii9. 
Edwards, M. S., \& Ashkenazy, N. M. (2018). Emotions and failure in academic life: Normalising the experience and building resilience. Journal of Management \& Organization, 24, 167-188. doi:10.1017/jmo.2018.20

Grossmann, D. (2014, January 24). Secret Google lab "rewards staff for failure.” BBC News. Retrieved from www.bbc.com/news/technology-25880738.

Heifetz, R. A., Linsky, M., \& Grashow, A. (2009). The practice of adaptive leadership: Tools and tactics for changing your organization and the world. Cambridge, MA: Harvard Business Press.

Jarvis, P. (2012). Adult learning in the social context. Oxford, England: Routledge.

Loscalzo, J. (2014). A celebration of failure. American Heart Association Journal, 129, 953-955. doi:10.1161/CIRCULATIONAHA.114.009220

Mezirow, J. (1994). Understanding transformation theory. Adult Education Quarterly, 44, $222-232$. doi:10.1177/074171369404400403

Robinson, K. (with Aronica, L.). (2009). The element: How finding your passion changes everything. New York, NY: Viking.

Rolfe, H (2010). Learning to take risks, learning to succeed [NESTA report]. Retrieved from https://www.nesta.org.uk/report/learning-to-take-risks-learning-to-succeed/

van Woerkom, M. (2012). Relationships between team characteristics, error orientation and team innovation. In J. Bauer \& C. Harteis (Eds.), Human fallibility: The ambiguity of errors for work and learning (pp. 127-140). Dordrecht, Netherlands: Springer.

Wang, W., Wang, B., Yang, K., Yang, C., Yuan, W., \& Shanghao, S. (2018). When project commitment leads to learning from failure: The roles of perceived shame and personal control. Frontiers in Psychology. doi:10.3389/fpsyg.2018.00086

Wizel, M. (2018). Preparing educational hackers. In Y. Weinberger \& Z. Libman (Eds.), Contemporary pedagogies in teacher education and development. Retrieved from IntechOpen https://www.intechopen.com/books/contemporary-pedagogies-in-teacher-education-anddevelopment/preparing-educational-hackers 